DOI: $10.17805 /$ zpu.2019.3.18

\title{
Социальное служение РПЦ: взаимодействие институтов государства и церкви в области социальных программ
}

\author{
М. Г. СОЛНЫШКИНА \\ МОСКОВСКИЙ ГУМАНИТАРНЫЙ УНИВЕРСИТЕТ, \\ Т. Д. МИРОНОВА \\ НЕЗАВИСИМЫЙ ИССЛЕДОВАТЕЛЬ
}

Социальное служение РПЦ и взаимодействие институтов государства и церкви в области социального служения исследуются на базе концепции паритетности социальных и культурных подходов. Социокультурный подход обладает эвристическим потенциалом, открывающим возможности для изучения взаимосвязи социального и культурного аспектов социального служения РПЦ и взаимодействия институтов государства и церкви в области социальных программ как ключевых моментов его развития и регулирования с позиций социокультурной динамики.

Исследованы структура церковно-социальной деятельности и основные направления социальной работы, проанализированы общественно-политические и организационноправовые основы развития взаимодействия институтов государства и церкви в области социального служения. Приводятся результаты социологического опроса прихожан храма в социальном служении Русской православной церкви (2018 г., 124 человека, г. Дмитров). Отмечено, что к наиболее значимым ценностно-мотивационным факторам социального служения относятся мотивы самореализации личности и сострадания. 
Результаты проведенного исследования позволили сформировать рекомендации по развитию социального служения РПЦ в режиме взаимодействия с профессиональным сектором социальной работы с учетом мотивационных факторов прихожан и других ресурсов социокультурной среды социального служения.

Ключевые слова: Русская православная церковь; социальное служение; социальная программа; государство и церковь; церковно-социальная деятельность

\section{BВЕАЕНИЕ}

Овременный этап развития общества характеризуется необходимостью оказания социальной помощи слабозащищенным категориям населения в ситуации социального риска, основные ресурсы которой сосредоточены преимущественно в профессиональном секторе социальной работы. В условиях трансформирующегося общества, когда государство испытывает недостаток ресурсов для решения столь важных задач по предоставлению социальных гарантий, особое значение приобретает взаимодействие с Русской православной церковью, имеющей разносторонний опыт социального служения с первых веков христианства и до наших дней (Гараджа, 2010: 26). Реализуется оно во взаимосвязи религиозной, благотворительной и социальной деятельности, осуществляется в направлениях медицинских, антиалкогольных, детских программ, патронажной помощи.

Изучение социального служения РПЦ и взаимодействия институтов государства и церкви в области социальных программ в контексте социологической проблематики предполагает:

- исследование структуры церковно-социальной деятельности и основных направлений социальной работы;

- анализ общественно-политических и организационно-правовых основ развития взаимодействия институтов государства и церкви в области социального служения.

По мнению известного теоретика социокультурного подхода Н. И. Мапина, единство «культуры и социальности, образующееся и преобразующееся деятельностью человека» (Аапин, 2000: 3), определяет место действующих институтов и отношений в обществе в конкретный исторический момент. Авторы считают, что социокультурный подход обладает эвристическим потенциалом, открывающим возможности для изучения взаимосвязи и взаимовлияния социального и культурного аспектов социального служения РПЦ и взаимодействия институтов государства и церкви в области социальных программ как ключевых моментов его развития и регулирования с позиций социокультурной динамики (Сорокин, 1992: 218). Социокультурная динамика социального служения представлена с позиций анализа исторических корней взаимоотношений государства и церкви, становления, развития социального служения с применением историко-социологического подхода и закономерностей исторической динамики культуры социального служения РПЦ (Флиер, 2016: 110).

Социокультурный подходу к анализу социального служения РПЦ в области социальных программ, представленный в настоящей статье, предполагает:

- исследование духовного фундамента развития взаимодействия институтов государства и церкви в области социального служения и социокультурной среды социального служения;

- анализ системы ценностей и мотивационных характеристик участников социального служения.

Источниковой базой исследования «Участие прихожан храма в социальном служении РПЦ» (декабрь 2017 г. - апрель 2018 г.) явились результаты анкетирования 
членов трех православных общин г. Амитрова Московской области в возрасте от 15 до 65 лет (124 чел.).

\section{СОЦИЕТААЬНЫЙ УРОВЕНЬ АНААИЗА \\ СОЦИААЬНОГО САУЖЕНИЯ РПЦ И РАЗВИТИЯ ВЗАИМОАЕЙСТВИЯ \\ ИНСТИТУТОВ ГОСУААРСТВА И ЦЕРКВИ}

Анализ социального служения РПЦ в рамках социетального подхода показал, что в настоящее время содержание церковной социальной работы структурировано и осуществляется на общецерковном, епархиальном, благочинническом и приходском уровнях.

На общецерковном уровне координацию церковно-социальной деятельности осуществляет Синодальный отдел по церковной благотворительности и социальному служению. Задачи данного отдела: подготовка проектов соглашений с государственными органами власти и типовых соглашений для использования в епархиях; разработка методических материалов по отдельным направлениям социального служения (в зависимости от категории нуждающихся в помощи) и распространение в епархиях; организация регулярных обучающих семинаров для должностных лиц и добровольцев, участвующих в социальном служении церкви; разработка курсов для духовных и общеобразовательных заведений Русской православной церкви по организации и осуществлению социальной работы; взаимодействие с государственными структурами с целью совершенствования законодательства и подзаконных актов для развития возможностей церковно-социальной работы.

Структура церковно-социальной деятельности и основных направлений социальной работы на епархиальном уровне выявлена нами через изучение деятельности функциональных подразделений Московской епархии - епархиальных отделов и характеристик взаимодействия их с государственными и общественными структурами ${ }^{1}$. Церковно-социальная деятельность как одна из областей сотрудничества церкви и государства в настоящее время представляет собой систему межсекторного социального взаимодействия государственных служб социальной работы и РПЦ в следующих направлениях: помощь Вооруженным силам, правоохранительным и медицинским учреждениям, деятельность по социальному служению и благотворительности, а также реализация молодежных программ отдыха, паломничества и православного туризма².

Анализ общественно-политических и организационно-правовых основ развития взаимодействия институтов государства и церкви в области социального служения показал, что государством созданы необходимые условия участия института церкви в реализации социальных программ и проектов в различных областях общественной жизни. Например, на федеральном уровне с 2011 г. действует соглашение между РПЦ и Министерством заравоохранения и социального развития РФ (подписано Патриархом Кириллом и Т. А. Голиковой 8 июля 2011 г.). В преамбуле договора провозглашается принцип сотрудничества светской власти и церкви в сфере социальной защиты населения. Аанное соглашение определяет области, направления и формы взаимного сотрудничества.

К организационно-правовым основам взаимодействия Русской православной церкви и государственных служб социальной работы на благочинническом и приходском уровнях относится разработка и реализация соглашений между подведомственными организациями региональных министерств социального развития, с одной сто- 
роны, и благочинническими округами и церковными приходами - с другой. В целом в современной России социальное служение РПЦ на основе взаимодействия государственных органов и церкви активно развивается и конкретизируется в результатах церковно-социальной деятельности. В 2017 г. в монастырях и на приходах РПЦ действовали более 2900 церковных социальных учреждений, проектов и инициатив; созданы 90 церковных детских приютов более чем для 1,5 тыс. детей; функционируют более 50 центров защиты материнства и детства, 61 приют для бездомных на 2047 мест, 62 приюта для наркозависимых на 1 тыс. человек; более чем в 20 епархиях открыты центры гуманитарной вещевой помощи.

\section{СОЦИОКУАЬТУРНЫЕ АСПЕКТЫ СОЦИААЬНОГО САУЖЕНИЯ РПЦ В ОБААСТИ СОЦИААЬНЫХ ПРОГРАММ}

1. Ауховный фундамент взаимодействия. Исторические корни взаимоотношений государства и церкви уходят во времена императора Константина, в правление которого христианство, освободившись от гонений первых трех веков после Рождества Христова, обрело статус государственной религии. Такие взаимоотношения получили название симфонии. Суть симфонии - взаимная поддержка, обоюдное сотрудничество государства и церкви, а также взаимная ответственность без вторжения одной стороны в сферу компетенции другой. Социальное служение Русской православной церкви имеет своей основой следование евангельским заповедям и апостольским правилам добра, справедливости, христианской любви и человеколюбия, помощи сирым и обездоленным, «окормления» бедных и немощных ${ }^{3}$. На этом духовном базисе объединяются цели и задачи церковно-социальной деятельности и государственных служб социальной работы. Таким образом, общность целей социальной политики государства, с одной стороны, и христианского милосердия и благотворительности Русской православной церкви, с другой стороны, образует духовный фундамент развития взаимодействия институтов государства и церкви в области социального служения.

2. Система иенностей и мотивачионных характеристик участников сочиально20 служения. На уровне церковной общины взаимодействие зависит от действенного приложения усилий большинства прихожан к формированию социального облика прихода и готовности к социальному служению. При этом приобщение к духовным ценностям происходит в активной деятельности по социальному служению.

Исследование «Участие прихожан храма в социальном служении РПЦ» проводилось в декабре 2017 г. - апреле 2018 г. Применяемый метод сбора первичной социологической информации - анкетирование, выборка стратифицированная. Обработано 124 анкеты. Выборка включает жителей г. Амитрова Московской области в возрасте от 15 до 65 лет, посещающих православные храмы с частотой от одного-двух раз в год до нескольких раз в неделю. Исследованием охвачены три православные общины г. Амитрова: храмов Введения Божией Матери, Святой Троицы, Казанской иконы Божией Матери.

В задачи исследования входили анализ отношения верующих к активному участию в социальной жизни церковной общины, изучение приоритетных форм социального служения и объектов социальной помощи; анализ мотивации социального служения прихожан.

Исследование форм и объектов благотворительной помощи в структуре социального служения показало, что в областях внешнего и внутреннего социально-церков- 
ного служения приоритетными считаются помощь многодетным семьям - денежная, натуральная, благотворительность (68\%), поддержка пожилых людей - социально-бытовая помощь, транспортные услуги (64\%), а также взаимодействие и участие в церковных мероприятиях на базе других храмов $(55 \%)$.

Мотивацию участия прихожан храма в церковно-социальном служении составляет система внутренних и внешних факторов, формирующих поведение, ориентированное на поддержку нуждающихся и базирующееся на духовных принципах сострадания, милосердия, безвозмездной помощи, готовности делиться опытом, талантом, временем. Отметим их тесную связь с принципами социальной работы (Холостова, 2013: 86). К наиболее значимым ценностно-мотивационным факторам социального служения относятся мотивы самореализации личности: ощущение востребованности в процессе общественно полезной деятельности, а также признание результатов со стороны других людей (см. таблицу) (Ковалева, 2013: 322).

\section{МОТИВАЦИОННЫЕ ФАКТОРЫ УЧАСТИЯ ПРИХОЖАН \\ В ЦЕРКОВНО-СОЦИАИЬНОМ САУЖЕНИИ (МНОЖЕСТВЕННЫЙ ВЫБОР) \\ MOTIVATIONAL FACTORS FOR PARISHIONERS' PARTICIPATION IN CHURCH SOCIAL SERVICE (MULTIPLE CHOICE)}

\begin{tabular}{|l|c|}
\hline \multicolumn{1}{|c|}{ Мотивационный фактор } & Bыбор, \% \\
\hline Востребованность в процессе общественно полезной деятельности & 78 \\
Желание помочь нуждающимся & 42 \\
Признание со стороны других людей & 62 \\
Четкое структурирование работы & 16 \\
\hline
\end{tabular}

Нами установлена корреляция ценностно-мотивационных факторов с частотой посещаемости храма и возрастными характеристиками участников социального служения. Респонденты, посещающие храм достаточно редко (раз в два месяца и реже), выделили ощущение востребованности (52\%) и заинтересованность общественно полезной работой (76\%), часто посещающие храм - признание со стороны других людей $(68 \%)$. Желание помочь окружающим как мотив участия в церковно-социальном служении характерно для молодежи (55\%) и прихожан старше 60 лет (64\%), а для прихожан возрастной категории от 35 до 60 лет характерен мотив ощущения востребованности в процессе общественно полезной работы (78\%). Внешний мотивационный фактор -организация и четкое структурирование церковно-социальной работы, относящийся к сфере социокультурной регуляции социального служения, наиболее значим для возрастной категории 35-60 лет.

Перечисленные ценностно-мотивационные факторы являются характеристиками социокультурной среды социального служения на уровне церковной общины и моделируют внешние и внутренние взаимодействия РПЦ при реализации социальных программ (Марков, Бирженюк, 2000: 8).

\section{ЗАКАЮЧЕНИЕ}

Сущность социального взаимодействия Русской православной церкви и государственных служб социальной работы состоит в координации усилий церкви и учреждений социальной сферы, имеющих общую направленность на сохранение социаль- 
ной стабильности общества. Анализ общественно-политических и организационноправовых основ развития взаимодействия институтов государства и церкви в области социального служения показал, что современное состояние этого сотрудничества отвечает задачам социального развития и социальной безопасности современной системы общественных отношений. Спектр основных направлений взаимодействия РПЦ и служб социальной работы (система церковно-социальной деятельности) соответствует структуре социальной политики государства и современным направлениям и профилям социальной работы. При этом наиболее адресно и продуктивно развиваются такие профили взаимодействия, как медико-социальная работа, социальная работа с молодежью, благотворительность в социальной работе. Они успешно объединяют усилия институтов государства и церкви в социальном служении.

Отметим эволюцию отношения к культуре в рамках комбинированной парадигмы «общества - культуры», выражающуюся категорией «социокультурное» как соотношением социального и культурного компонента в жизни общества. В основе этой концепции лежит представление о том, что социальная и культурная жизнь тесно взаимосвязаны и влияют друг на друга даже в случаях неочевидности такого влияния. Общность целей социальной политики государства, с одной стороны, и христианского милосердия и благотворительности Русской православной церкви, с другой стороны, образует духовный фундамент развития взаимодействия в области социального служения. Ценностно-мотивационные факторы субъектов социального служения: самореализация, сострадание, милосердие, благотворительная помощь - являются характеристиками социокультурной среды на уровне церковной общины и моделируют внешние и внутренние взаимодействия РПЦ при реализации социальных программ.

Результаты проведенного исследования позволили сформировать рекомендации по развитию социального служения РПЦ в режиме взаимодействия с профессиональным сектором социальной работы:

- использование функциональных подходов с ориентацией внутрицерковной социальной работы на интересы, потребности субъектов социального служения; структурная дифференциация деятельности по видам участия и объектам социальной помощи; формирование стратегии социальной деятельности в рамках церковной общины с учетом мотивационных факторов прихожан;

- организация в режиме взаимодействия с профессиональными специалистами социальной работы реализации программ для многодетных семей, пожилых людей, оказание социальных услуг с использованием выявленных ресурсов социокультурной среды социального служения.

\section{ПРИМЕЧАНИЯ}

${ }^{1}$ Социальное служение Церкви современному российскому обществу на примере Московской епархии // Московская епархия Русской Православной Церкви. URL: http://www.mepar. ru/library/vedomosti/74/1573 (дата обращения: 15.04.2019).

2 Благотворительная и социальная деятельность религиозных организаций [Электронный pecypc] // Официальный сайт Московского Патриархата. URL: http://www.patriarchia.ru/db/ text/1281610.html (дата обращения: 18.04.2019).

3 Основы социальной концепции Русской православной церкви [Электронный ресурс] // Азбука веры. URL: https://azbyka.ru/otechnik/dokumenty/osnovy-sotsialnoj-kontseptsii-russkojpravoslavnoj-tserkvi/ (дата обращения: 17.04.2019). 
СПИСОК АИТЕРАТУРЫ

Гараджа, В. И. (2010) Социология религии : учеб. пособие / В. И. Гараджа. 4-е изд., перераб. и доп . М. : ИНФРА-М. 304 с.

Ковалева, А. И. (2013) Новый взгляд на явление идентичности // Знание. Понимание. Умение. № 2. С. 322-323.

Аапин, Н. И. (2000) Социокультурный подход и социетально-функциональные структуры // Социологические исследования. № 7. С. 3-12.

Марков, А. П., Бирженюк, Г. М. (2000) Основы социокультурного проектирования : учеб. пособие. СПб. : ИзА-во Санкт-Петербургского гуманитарного университета профсоюзов. 260 с.

Сорокин, П. (1992) Человек, цивилизация, общество : пер. с англ. / общ. ред., сост. и предисл. А. Ю. Согомонова. М. : Политиздат. 543 с.

Флиер, А. Я. (2016) Развитие теории исторической динамики культуры: взаимодействие социального и культурного факторов // Знание. Понимание. Умение. № 3. С. 109-112.

Холостова, Е. И. (2013) Энциклопедия социальных практик / под ред. Е. И. Холостовой, Г. И. Климантовой. 2-е изд. М. : Издательско-торговая корпорация «Аашков и К». 660 с.

Aата поступления: 30.05.2019 2.

\author{
SOCIAL SERVICE OF THE RUSSIAN ORTHODOX CHURCH: \\ THE INTERACTION OF STATE AND CHURCH INSTITUTIONS \\ IN THE FIELD OF SOCIAL PROGRAMS \\ M. G. SOLNYSHKINA \\ MOSCOW UNIVERSITY FOR THE HUMANITIES \\ T. D. MIRONOVA \\ INDEPENDENT RESEARCHER
}

The social service of the Russian Orthodox Church and the interaction of the institutions of the state and the church in the field of social service are researched on the basis of the concept of parity of social and cultural approaches. The sociocultural approach has a heuristic potential that opens up opportunities to study the relationship between the social and cultural aspects of the social service of the Russian Orthodox Church and the interaction of the state institutions and the church institutions in the field of social programs as key points of its development and regulation from the standpoint of socio-cultural dynamics.

The structure of church social activity and the main directions of social work were researched; the socio-political and organizational-legal foundations of the development of interaction between state and church institutions in the field of social service were analyzed. The results of a sociological survey of parishioners of the church in the social ministry of the Russian Orthodox Church 2018,124 people, Dmitrov) are presented. It is noted that the most significant value-motivational factors of social service include motives of self-realization of personality and compassion.

The results of the study made it possible to formulate recommendations on the development of the Russian Orthodox Church's service in the mode of interaction with the professional sector of social work, taking into account motivational factors of parishioners and other resources of the social and cultural environment of social service.

Keywords: Russian Orthodox Church; social service; social program; state and church; church and social activities

\title{
REFERENCES
}

Garadzha, V. I. (2010) Sotsiologiia religii : ucheb. posobie / V. I. Garadzha. 4nd ed. Moscow, Infra-M. 304 p. (In Russ.).

Kovaleva, A. I. (2013) Novyi vzgliad na iavlenie identichnosti. Znanie. Ponimanie. Umenie, no. 2, pp. 322-323. (In Russ.).

Lapin, N. I. (2000) Sotsiokul'turnyi podkhod i sotsietal'no-funktsional'nye struktury. Sotsiologicheskie issledovaniia, no. 7, pp. 3-12. (In Russ.). 
Markov, A. P. and Birzheniuk, G. M. (2000) Osnovy sotsiokul'turnogo proektirovaniia : ucheb. posobie. St. Petersburg, Izd-vo Sankt-Peterburgskogo gumanitarnogo universiteta profsoiuzov. $260 \mathrm{p}$. (In Russ.).

Sorokin, P. (1992) Chelovek, tsivilizatsiia, obshchestvo : transl. from Engl./ed. by A. Iu. Sogomonov. Moscow, Politizdat. 543 p. (In Russ.).

Flier, A. Ia. (2016) Razvitie teorii istoricheskoi dinamiki kul'tury: vzaimodeistvie sotsial'nogo i kul'turnogo faktorov. Znanie. Ponimanie. Umenie, no. 3, pp. 109-112. (In Russ.).

Kholostova, E. I. (2013) Entsiklopediia sotsial' nykb praktik / ed. by E. I. Kholostova and G. I. Klimantova. 2nd ed. Moscow, Izdatel'sko-torgovaia korporatsiia «Dashkov i K ». 660 p. (In Russ.).

Submission date: 30.05.2019.

Солнышкина Марина Георгиевна - доктор социологических наук, профессор, профессор кафедры социологии Московского гуманитарного университета. Адрес: 111395 Москва, ул. Юности, А. 5. Тел.: +7 (499) 374-60-21. Эл. адрес: solny2001@mail.ru

Миронова Татьяна Аавыдовна - независимый исследователь, помощник настоятеля Троицкого храма г. Амитрова по социальной работе. Адрес: 141982, Московская область, г. Аубна, ул. Университетская, А. 19. Тел.: +7 (496) 216-60-67; +7 (963) 771-59-98. Эл. aдpec: galadriel2099@yandex.ru

Solnyshkina Marina Georgievna, Doctor of Sociology, Professor, Professor, Sociology Department, Moscow University for the Humanities. Postal address: 5, Yunosti St., Moscow, Russian Federation, 111395. Tel.: +7 (499) 374-60-21. E-mail: solny2001@mail.ru

Mironova Tatyana Davydovna, Independent Researcher, Assistant Abbot for Social Work, Trinity Church of Dmitrov. Postal address: 19, Universitetskaya St., Dubna, Moscow Region, Russian Federation, 141982. Tel.: +7 (496) 216-60-67; +7 (963) 771-59-98. E-mail: galadriel2099@yandex.ru 